\title{
Airway management of post burn contracture neck - a case report
}

\author{
Chethanananda T.N ${ }^{1}$, Sanjay B.G ${ }^{2}$, Aasthaa ${ }^{3}$, Mahalakshmi ${ }^{4}$, Chaithra G.V ${ }^{5}$ \\ ${ }^{1}$ Dr Chethanananda T.N. MBBS, DA, DNB, Professor, Department of Anaesthesia, ${ }^{2}$ Dr.Sanjay B.G MBBS, DA, Senior \\ resident, Department of Anaesthesia, ${ }^{3} \mathrm{Dr}$ Aasthaa MBBS Post Graduate resident, Department of Anaesthesia, ${ }^{4} \mathrm{Dr}$ \\ Mahalakshmi MBBS, Post Graduate resident, Department of Anaesthesia, ${ }^{5}$ Dr Chaithra G.V MBBS, Post Graduate \\ resident, Department of Anaesthesia. All are affiliated with Adichunchanagiri Institute of Medical Sciences, \\ Balagangadharanatha Nagara-571448, Nagamangala Taluk, Mandya District, Karnataka, India
}

Address for correspondence: Dr. Aasthaa, Email: dr.aasthaa.khurana@gmail.com

\begin{abstract}
The Anaesthetic management of patients with post burn contracture release poses many problems to anaesthesiologist. Airway management in such cases is still challenging to anaesthesiologist as the contracture and deformity due to fibrous tissue resulting in non-alignment of oral, pharyngeal and laryngeal planes, makes laryngoscopy and endotracheal intubation very difficult or impossible and this can result in many life threatening and serious complications. We report the successful airway management of a patient with restricted neck extension and fixed flexion deformity by awake nasal fibreoptic bronchoscope guided nasotracheal intubation.
\end{abstract}

Keywords: Post burn Contracture, Fibreoptic Bronchoscope, Difficult Airway

\section{Introduction}

Management of airway in patients with orofacial and neck burn contracture is often a challenge to the anaesthesiologist. It is so because of the restricted mouth opening, decreased oropharyngeal space, limited extension at the atlanto-occipital joint, reduced compliance of the submandibular space and presence of fibrosed tissue over the neck [1]. The reported incidence of Difficult Intubation is $5.85 \%$, Cannot Intubate situation is $0.35 \%$ and Cannot Intubate-Cannot Ventilate situation is $0.02 \%$ and these can be major causes of anaesthesia related morbidity and mortality [2].

We report the successful anaesthetic management of a patient with severely limited neck movements associated with limited mouth opening by awake nasal fibre optic bronchoscopic guided intubation.

\section{Case Report}

A 40 year old male patient weighing $55 \mathrm{kgs}$ ASA grade I had presented with severe burns over chin (lower jaw),

Manuscript received: $4^{\text {th }}$ Oct 2015

Reviewed: $10^{\text {th }}$ Oct 2015

Author Corrected: $24^{\text {th }}$ Oct 2015

Accepted for Publication: $9^{\text {th }}$ Nov 2015 neck and trunk area (35\%), of six months duration with fibrosed scar tissue that was extending from neck involving lower jaw, anterolateral aspect of neck, upper anterior chest wall and upper abdomen. His medical history was insignificant.

On examination fibrosed scar was present over the lower jaw, anterior neck Fig. (1) with a slightly fixed flexion deformity with Mouth Opening< 2 FingersFig.(2) Mallampati Grading was Grade IV. Thyromental Distance could not be assessed because of distorted neck anatomy. Trachea was not palpable and no extension and Lateral Rotation of neck were possible. He was planned for Contracture Release and Skin Grafting. A thorough pre-operative airway evaluation and preparation was done keeping all the airway gadgets to manage anticipated difficult airway. We planned awake nasal fibreoptic bronchoscope guided intubation with an alternative option as tumescent mixture administration and release of contracture of neck, then direct laryngoscopic aided endotracheal intubation if nasal fibre optic intubation fails. Procedure explained to patient and Written Informed Consent taken including for the surgical release of contracture and tracheostomy if required. 


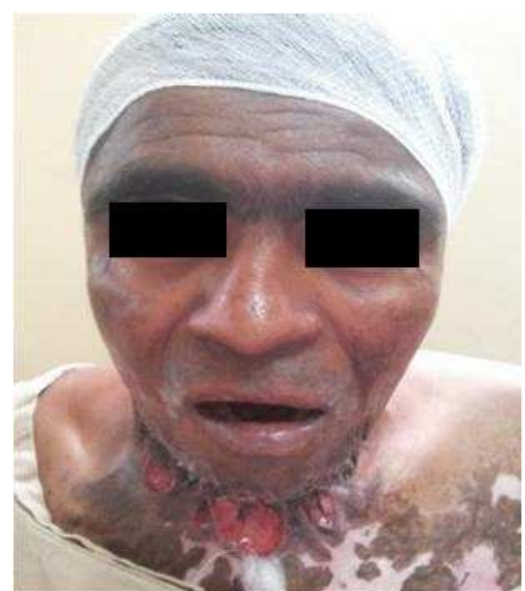

Fig. (1)

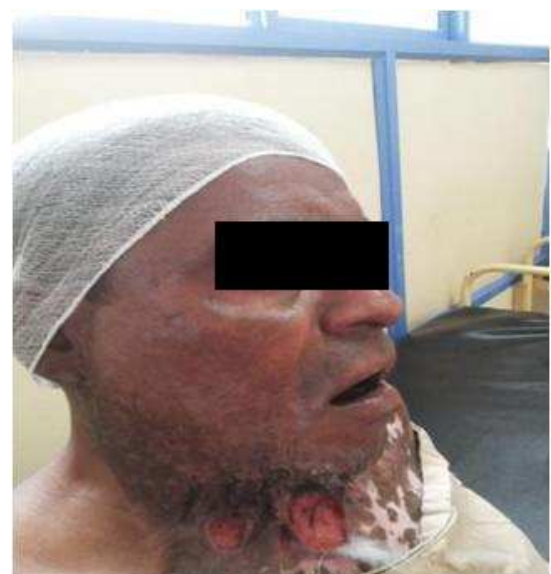

Fig. (2)

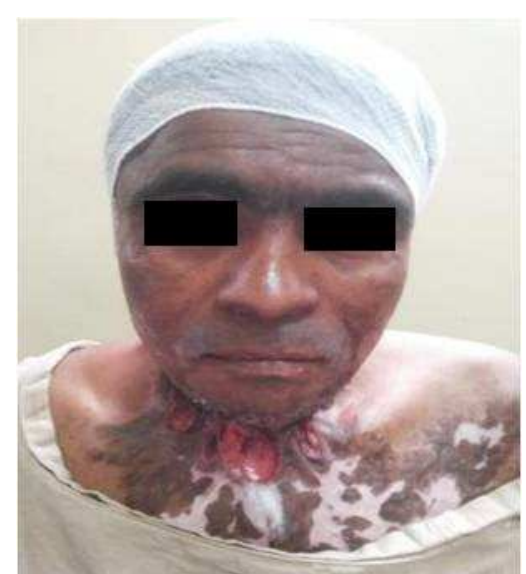

Fig. (3)

\section{Anaesthetic Management}

Pre-operatively Nebulization with $2 \mathrm{ml}$ of $4 \%$ Lignocaine was given half an hour before surgery. All the gadgets to manage Difficult Airway kept ready. ENT surgeon was requested to be available standby. IV access was secured with $18 \mathrm{G}$ cannula and standard monitors attached [with $\mathrm{ETCO}_{2}$ ]. Inj. Ranitidine $50 \mathrm{mg}+$ Inj. Ondansetron $4 \mathrm{mg}+\mathrm{Inj}$. Glycopyrrolate $0.2 \mathrm{mg}$ was given as premedication.

Pre-operative airway preparation was done by gargling $10 \%$ Lignocaine viscus $10-15$ minutes before procedure and posterior pharyngeal wall was sprayed with $10 \%$ Lignocaine spray. Xylometazoline drops $0.1 \%$ was instilled through nose for decongestion along with $2 \%$ Lignocaine gel application.
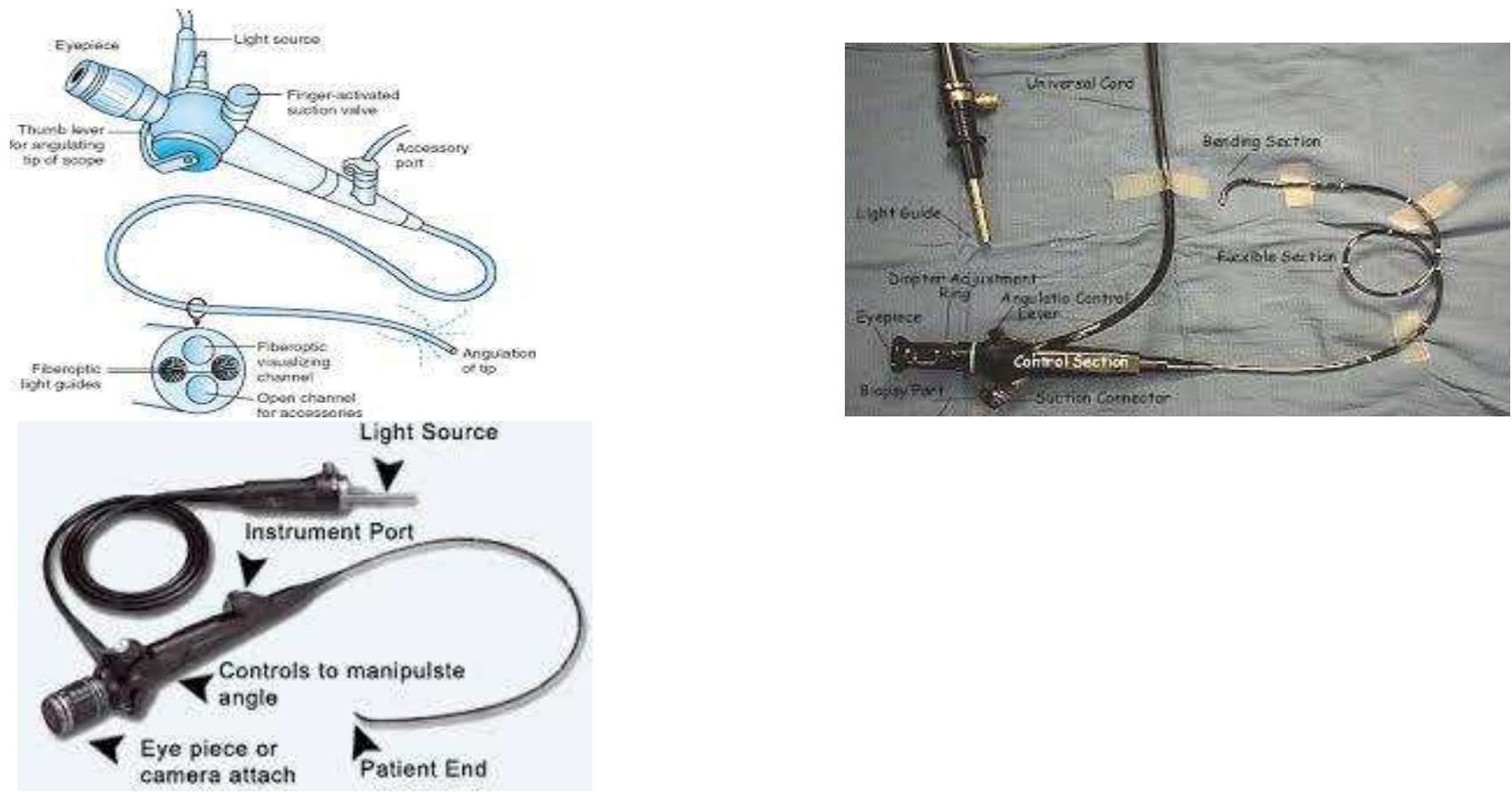

A slight head low position with 30 degree elevation of head end was done. Preoxygenation with $100 \% \mathrm{O}_{2}$ was done for about 5 minutes and the fibre optic guided intubation attempted with $6.5 \mathrm{~mm}$ ID cuffed portex ET tube and Endotracheal tube threaded over $3.5 \mathrm{~mm}$ adult bronchoscope in the Right nasal cavity and spray as you go technique was done with $5 \mathrm{ml}$ of $2 \%$ Lignocaine as the scope reached the vocal cord and down the trachea. When the Carina was visualised the 
scope stabilised with Left hand and ET tube was negotiated over the scope into the trachea and the bronchoscope was slightly withdrawn so that the tip of ET tube could be seen. Then the bronchoscope was taken out securing the ET Tube and its proper position was confirmed.

Later patient was induced with IV propofol $100 \mathrm{mg}$ and fentanyl $80 \mathrm{mcg}$. Anaesthesia maintained with $\mathrm{O}_{2}+\mathrm{N}_{2} \mathrm{O}+$ Sevoflurane + Inj. Atracurium on Intermittent Positive Pressure Ventilation. Surgery was completed in 2 hour 30 minutes. Vitals were stable. Neuromuscular monitor guided reversal of neuromuscular blockade was done with IV Neostigmine + glycopyrolyte once the spontaneous respiration started. Reversal was done, extubation considered and patient monitored in post anaesthetic recovery room for 2 hours, then shifted to post operative ward

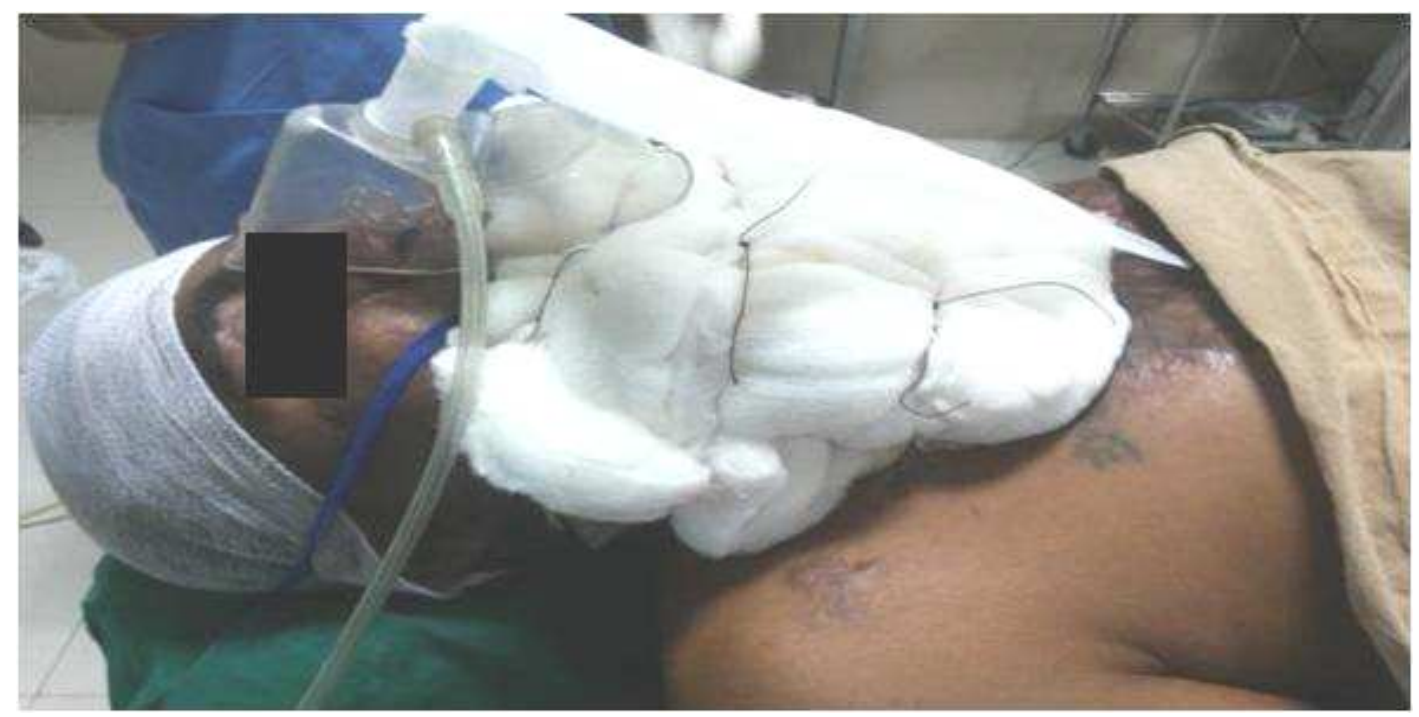

Fig 4: Post intubation

\section{Discussion}

Post burn neck contracture following burns is a known complication and airway management in such patients offer a challenge. The fixed flexion deformity of head causes difficult Endotracheal intubation as there will be limited oro-pharyngeal space, decreased pharyngeal space, decreased atlanto-occipital extension and submandibular compliance. Many options are available for intubation in such cases like: awake fibreoptic intubation, Laryngeal Mask Airway, Intubation Laryngeal Mask Airway, Blind nasal intubation, Retrograde intubation, tracheostomy, Release of contracture using tumescent mixture of local anaesthetic but the use of fibre optic intubation is the gold standard when compared to other techniques [3,4]. In our case use of standard Laryngoscopy, the insertion of Supraglottic airway device like Laryngeal Mask Airway or Intubation Laryngeal Mask Airway and retrograde intubation was not possible as there was limited mouth opening. Tracheostomy was not suitable as there was fibrosed tissue over the neck making anatomy distorted. However in patient with extreme deformity the functional and anatomical distortion may be such that all attempts at intubation may fail [5]. Hence the primary plan for airway management of our patient was awake nasal Fibre optic bronchoscope guided intubation with a backup plan of tumescent anaesthesia for contracture release followed by direct laryngoscope and endotracheal intubation.

Fibreoptic bronchoscope guided intubation is considered as safest and most effective method in known or suspected cases of difficult intubation. The primary advantage of Fibreoptic Bronchoscope guided intubation is that it permits direct visual control of the intubation procedures [5]. There are studies indicating the success rate of Fibreoptic Bronchoscope guided intubation of $88-100 \%$ in difficult airway patients $[6,7,8,9,10]$. Fibreoptic bronchoscopy provides excellent visualization of glottis and the endotracheal tube insertion can be continuously viewed until intubation is accomplished.

\section{Conclusion}


Vigilance and pre-anaestheticmeticulus preparation for difficult airway management is the key to successful management of difficult airways. The anaesthesiologist should have multi layered contingency plan to handle the airway. As attempts at direct laryngoscopy or Supraglottic insertions are extremely likely to fail and leads to complications in such patients, indirect attempts should be tried as first attempt. Proper preoperative preparation and intraoperative planning and a team work are always necessary for a successful outcome.

\section{Funding: None}

Competing interests: None declared

Ethical clearance: The study was approved by the institutional human ethical committee.

\section{References}

1. Sahajanandhan R, Saravanan PA, Ponniah M, Jacob JI, Gupta AK, Nambi GI. Post-burn contracture neck with extreme microstomia and fibrosed obliterated nose: a unique airway challenge. Natl Med J India. 2010 Sep-Oct;23(5):281-2.

2. Crosby ET, Cooper RM, Douglas MJ, Doyle DJ, Hung OR, Labrecque P, Muir H, Murphy MF, Preston RP, Rose DK, Roy L. The unanticipated difficult airway with recommendations for management. Can J Anaesth. 1998 Aug;45(8):757-76.

3. S.K. Singh, V. Asthana, Y.S. Payal S. Agarwal, D.K. Singh, N.Srivastava Airway Management in fixed flexion deformity using an alternative method of ILMA insertion. Ind. J Anaesth, 2008;52(4):440-442
4. Agrawal S, Asthana V, Meher R, Singh D K. Paraglossal Straight Blade Intubation Technique-an Old Technique Revisited in Difficult Intubations: A Series of 5 Cases. Indian J Anaesth [serial online] 2008 [cited 2015 Dec 10];52:317-20.

5. Kreulen M, Mackie DP, Kreis RW, Groenevelt F. Surgical release for intubation purposes in postburn contractures of the neck. Burns. 1996 Jun;22(4):310-2.

6. Bissinger U, Guggenberger H, Lenz G. Retrogradeguided fiberoptic intubation in patients with laryngeal carcinoma. Anesth Analg. 1995 Aug;81(2):408-10.

7. Cohn AI, Zornow MH. Awake endotracheal intubation in patients with cervical spine disease: a comparison of the Bullard laryngoscope and the fiberoptic bronchoscope. Anesth Analg. 1995 Dec;81(6):1283-6.

8. Larson SM, Parks DH. Managing the difficult airway in patients with burns of the head and neck. J Burn Care Rehabil. 1988 Jan-Feb;9(1):55-6.

9. Reasoner DK, Warner DS, Todd MM, Hunt SW, Kirchner J. A comparison of anesthetic techniques for awake intubation in neurosurgical patients. J Neurosurg Anesthesiol. 1995 Apr;7(2):94-9.

10. Sidhu VS, Whitehead EM, Ainsworth QP, Smith M, Calder I. A technique of awake fibreoptic intubation. Experience in patients with cervical spine disease. Anaesthesia. 1993 Oct;48(10):910-3.

\section{How to cite this article?}

Chethanananda TN, Sanjay BG, Aasthaa, Mahalakshmi, Chaithra GV. Airway management of post burn contracture neck - a case report. Int J Med Res Rev 2015;3(10):1265-1268. doi: 10.17511/ijmrr.2015.i10.229. 